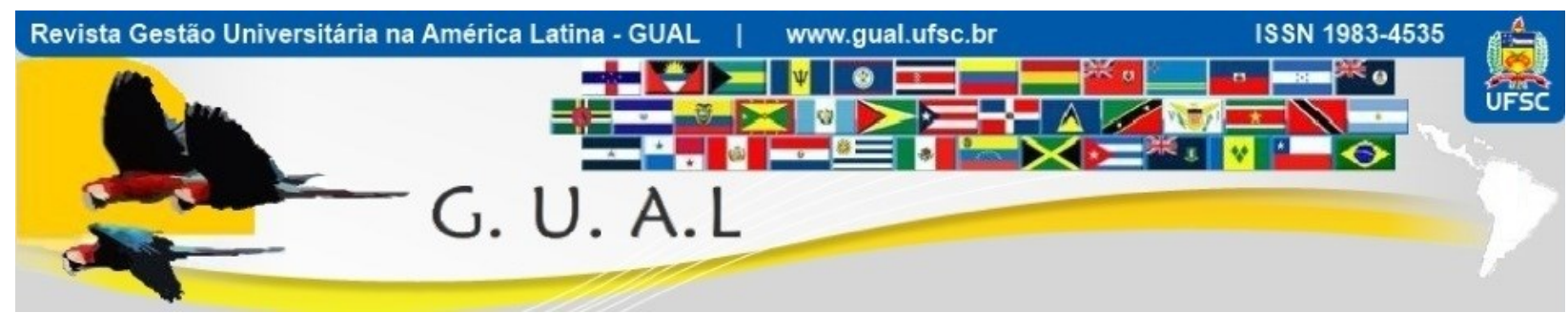

DOI: http://dx.doi.org/10.5007/1983-4535.2018v11n2p1

\title{
O PAPEL DO ADMINISTRADOR NA ESTRUTURA ACADÉMICA DA UNIVERSIDADE FEDERAL DO RIO GRANDE: UMA ANALISE COM BASE NO DISCURSO DO SUJEITO COLETIVO
}

THE ROLE OF THE ADMINISTRATOR IN THE ACADEMIC STRUCTURE OF THE FEDERAL UNIVERSITY OF RIO GRANDE: AN ANALYSIS BASED ON THE DISCOURSE OF THE COLLECTIVE SUBJECT

Rodrigo Serpa Pinto, Doutor Universidade Federal de Pelotas - UFPEL serparg@ufpel.edu.br

Adalice Andrade Kosby, Especialista Universidade Federal de Pelotas - UFPEL adalicekosby18@gmail.com

Recebido em 06/abril/2017

Aprovado em 20/março/2018

Sistema de Avaliação: Double Blind Review

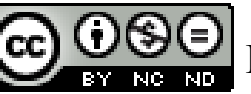

Esta obra está sob uma Licença Creative Commons Atribuição-Uso. 


\title{
RESUMO
}

Esta pesquisa teve como objetivo investigar a percepção dos Administradores acerca do papel que desempenham nas Unidades Acadêmicas da Universidade Federal do Rio Grande FURG, com base no Discurso do Sujeito Coletivo (DSC). O intuito era identificar se havia clareza por parte dos Diretores das Unidades quanto ao papel a ser desempenhado pelos Administradores, especialmente no que tange ao conhecimento das atribuições constantes na descrição do cargo; bem como o sentimento desses profissionais em relação às funções que desempenham e ao futuro do seu papel como Administrador de Unidade Acadêmica da Instituição. A técnica do DSC consiste ainda em analisar o material escrito coletado, extraindo-se de cada um dos questionários as ideias centrais e ancoragens, assim como suas correspondentes expressões-chave, que compõem um ou vários discursos-síntese, na primeira pessoa do singular. A análise dos dados, por meio do Discurso do Sujeito Coletivo, forneceu condições para perceber os diferentes entendimentos sobre o fazer do Administrador nas Unidades Acadêmicas e a dificuldade de padronização das atividades desse profissional, bem como a necessidade de apoio da Instituição na construção de uma proposta sólida para aproximar esses papeis dentro das Unidades.

Palavras-chave: Percepção do Administrador. Unidades Acadêmicas. Discurso do Sujeito Coletivo.

\begin{abstract}
This research had as objective to investigate the perception of the Administrators about the role they play in the Academic Units of the Federal University of Rio Grande - FURG, based on the Discourse of the Collective Subject (DSC). The purpose was to identify whether there was clarity on the part of the Directors of the Units as to the role to be played by the Directors, especially as regards the knowledge of the duties included in the job description; As well as the feeling of these professionals in relation to the functions they perform and to the future of their role as Administrator of Academic Unit of the Institution. The DSC technique also consists of analyzing the collected written material, extracting from each of the questionnaires the central ideas and anchorages, as well as their corresponding key expressions, which make up one or several speech-synthesis, in the first person singular. The analysis of the data, through the Collective Subject Discourse, provided conditions to understand the different understandings about the actions of the Administrator in the Academic Units and the difficulty of standardizing the activities of this professional, as well as the need for support from the Institution in the construction of a Solid proposal to bring these roles closer to the Units.
\end{abstract}

Keywords: Perception of the Administrator. Academic Units. Discourse of the Collective Subject 


\section{INTRODUÇÃO}

A profissão de Administrador, reconhecida em 09 de setembro de 1965, completou 50 anos. Essa data histórica nos faz refletir sobre o papel desse profissional em organizações públicas; tema esse pouco explorado até então, mas que fez parte das discussões no decorrer do ano de 2015 dentro dos Conselhos Regionais de Administração e certamente deverá ocupar uma posição de destaque nos próximos anos. É primordial que os Administradores se engajem nessa pauta, refletindo sobre a importância da figura do Administrador na contribuição de uma gestão pública de qualidade (LEMOS, 2015).

Desse modo, tem-se discutido a necessidade de profissionalizar a gestão pública, destacando-se a importância de se implantar técnicas e ferramentas utilizadas pelos profissionais graduados em administração para melhoria da gestão; bem como a importância de se ter um profissional Administrador com um olhar diferenciado, voltado à redução de custos, diminuição de desperdício em especial sobre a gestão de pessoas, no setor público.

Sendo assim, é pertinente que se introduzam conceitos e ferramentas da ciência da Administração na gestão de Órgãos e Instituições Públicas, como é o caso das Universidades. Ademais, é necessário um Administrador para pensar além dos paradigmas existentes e modificar tais organizações que, podem não apresentar tantos problemas de estrutura, mas sim de gestão. Mas, para que essas mudanças gradativamente possam acontecer dentro do setor público, especificamente nas Universidades, será preciso um esforço conjunto de toda a para que haja um maior reconhecimento e valorização do profissional graduado em Administração em detrimento ao técnico, o qual ocupa o cargo de gestor.

Nesse contexto, a Universidade Federal do Rio Grande (FURG), aproveitando a oportunidade de expansão dada pelo REUNI (Programa de Expansão e Reestruturação das Universidades Públicas Federais Brasileiras) inovou, e, em 2009 através do Edital nº 01, abriu processo seletivo para contratação, via concurso público, de profíssionais graduados em Administração. Esses foram admitidos com o intuito de atuarem na melhoria da gestão da Universidade, mais especificamente nas Unidades Acadêmicas.

Nesse sentido, essa pesquisa tem como objetivo geral investigar a percepção dos Administradores acerca do papel que desempenham nas Unidades Acadêmicas da Universidade Federal do Rio Grande - FURG, com base no Discurso do Sujeito Coletivo (DSC). Para o atendimento do objetivo geral, foram traçados objetivos específicos, analisados com base no Discurso do Sujeito Coletivo (DSC), e apresentados na análise deste artigo. O 
intuito era identificar se havia clareza por parte dos Diretores das Unidades quanto ao papel a ser desempenhado pelos Administradores, especialmente no que tange ao conhecimento das atribuições constantes na descrição do cargo; bem como o sentimento desses profissionais em relação às funções que desempenham e ao futuro do seu papel como Administrador de Unidade Acadêmica da Instituição.

\section{REFERENCIAL TEÓRICO}

O Referencial Teórico apresentado a seguir visa dar sustentação e embasamento aos temas envolvidos na pesquisa, e abordará a Gestão Universitária e o Papel do Administrador no Setor Público.

\subsection{GESTÃO UNIVERSITÁRIA}

As instituições universitárias são organizações dotadas de características próprias: objetivos difusos; decisões com interferência de diversos grupos; cunho político predominando nas decisões; desempenho com dificuldades de quantificação; profissionalismo e competência, dentre outras. Além disso, destaca-se que as universidades detêm o poder de interagir com um vasto número de segmentos da sociedade, devido seu caráter interdisciplinar, em detrimento a qualquer outra organização isoladamente. Sendo assim, normalmente os problemas que se apresentam são de gestão. Portanto, é imprescindível que as IES saibam gerir seus recursos, muitas vezes escassos, a fim de garantirem competitividade frente às demandas que se apresentam. Para isso, o gestor universitário necessita de ferramentas de gestão que possibilitem a resolução desses problemas (SILVA, 2013). Na visão de Andrade e Souza (2013), as Universidades Federais Brasileiras apresentam falhas e dificuldades na prática da gestão. Atualmente, as universidades estão passando por mudanças e vêm enfrentando o desafio de desenvolver um papel totalmente diferenciado do tradicional. Algumas dessas mudanças vêm acontecendo com diversos tipos de organizações, e consequentemente estão influenciando também as universidades em prol de melhores resultados, de custos administrativos e operacionais mais baixos (JUNIOR e RIZZATTI, 2004). Os autores reforçam que a administração universitária possui um contexto diferenciado em relação à administração de empresas privadas e também da própria administração pública em geral. Eles defendem a ideia de que, da mesma maneira como não se deve gerenciar instituições públicas como se gerencia uma organização privada, a administração universitária 
tem suas formas diferenciadas de gestão. Além disso, também entendem que uma das dificuldades das Universidades Brasileiras é de cunho administrativo e está relacionada à falta de conhecimentos teóricos da função administrativa por parte dos gestores, fazendo com que a gestão das universidades seja desenvolvida de maneira pouco profissional. Nesse contexto, Júnior e Lopes (2015), concordam que um dos principais problemas enfrentados pelos gestores universitários é a obtenção de uma postura de gestão diversificada, em função da natureza complexa dessas organizações. Tal ambiente exige gestores com diversas habilidades: criativos, inovadores, sensíveis, racionais, intuitivos e acima de tudo, corajosos nas tomadas de decisões.

\subsection{O PAPEL DO ADMINISTRADOR NA GESTÃO DAS ORGANIZAÇÕES PÚBLICAS}

Em um sentido amplo, administrar é uma prática dinâmica que está relacionada à tomada de decisão sobre o uso de recursos e objetivos. Onde existir pessoas fazendo uso de recursos em busca de atingir algum objetivo, a prática da administração estará presente. $\mathrm{O}$ propósito principal do processo de administrar é dar subsídios à realização de objetivos por meio de aplicação de recursos, através de controles (SILVA, 2013).

Conforme Lemos (2015), diante das dificuldades vivenciadas no setor público nos dias de hoje, existe uma necessidade de se discutir a administração pública e pensar em um modelo de gestão pública ideal, e, para que se consiga construí-lo, não só necessitamos da presença de um Administrador como também do conhecimento técnico da profissão, com o intuito de desenvolver conceitos novos e aplicar metodologias de forma transparente. Como já exposto, para que isso se tornasse possível, se fez necessário legalizar o exercício da profissão de Administrador no Brasil e esse processo se deu em 09 de setembro de 1965, tornando-se um marco de conhecimento e valorização do profissional. Como forma de resguardar o mercado de trabalho para os que já atuavam como Administradores públicos e proteger a sociedade de pessoas que não possuíam habilitação para exercer a profíssão, surgiu a necessidade de que a mesma fosse institucionalizada. Esses profissionais, na época, eram chamados de Técnicos em Administração e em 1985 foi aprovado um projeto de lei que, após três anos de tramitação na Câmara Federal, possibilitou a troca da nomeação para Administradores. Esse foi o início de uma grande luta dos Conselhos Regionais de todo o Brasil pela valorização da profissão (BARATZ, 2015). 
Após longos anos de luta, através da Lei $n^{\circ}$ 4769/65, foi instituída a profissão de Administrador. Através do Decreto-lei $\mathrm{n}^{\circ}$ 61.934/67, esta lei foi regulamentada e no seu capítulo II, artigo $3^{\circ}$, deixa claras as atividades inerentes ao profissional Administrador (ANDRADE; SOUZA, 2013):

a) a elaboração de pareceres, relatórios, planos, projetos, arbitragens e laudos, em que se exija a aplicação de conhecimentos inerentes às técnicas de organização;

b) o desenvolvimento de pesquisa, estudo, análise, interpretação, planejamento, implantação, coordenação e controle de trabalhos no campo da Administração Geral, como administração e seleção de pessoal, organização, análise, métodos e programas de trabalho, orçamento, administração de material e financeira, administração mercadológica, administração de produção e de relações industriais, bem como de outros campos em que estes se desdobrem ou com os quais sejam conexos;

c) o exercício de funções e cargos como administrador do Serviço Público Federal, estadual, Municipal e Autárquico, de Sociedades de Economia Mista, de Empresas Estatais, Paraestatais, Privadas e de Organizações não governamentais (ONG), em que fique expresso e declarado o título do cargo abrangido;

d) o exercício de funções de chefia ou direções intermediárias ou superior, de assessoramento e consultoria em órgãos ou seus compartimentos da Administração Pública ou de entidades privadas, cujas atribuições envolvam principalmente a aplicação de conhecimentos inerentes às técnicas de administração;

e) o magistério em matérias técnicas do campo da Administração e Organização (BRASIL, 1965).

Em vista das atividades previstas em Lei e a diversidade de campo de atuação do profissional Administrador, se faz necessário termos o conhecimento das atividades elencadas no edital $\mathrm{n}^{\mathrm{o}} 01$ de 2009, o qual abriu processo seletivo por meio de concurso público à Universidade Pública em estudo, conforme a lei 8112 de dezembro de 1990, a descrição sumária do cargo de Administrador é a seguinte:

Administrador: planejar, organizar, controlar e assessorar as organizações nas áreas de recursos humanos, patrimônio, materiais, informações, financeira, tecnológica, entre outras; implementar programas e projetos; elaborar planejamento organizacional; promover estudos de racionalização e controlar o desempenho organizacional; prestar consultoria administrativa. Assessorar nas atividades de ensino, pesquisa e extensão (FURG, 2009).

Diante da gama de atividades as quais um Administrador poderá desenvolver de acordo com as atribuições do seu cargo e, pensando no papel desses nas Universidades, que é 
o caso do estudo em questão, Júnior e Lopes (2015) identificam que não é fácil se ter clareza das funções de um Administrador na sociedade vigente, e maiores dificuldades se tem ainda em analisar o real papel que esses vêm desempenhando nas Universidades. Isso se deve pelos desafios relacionados às complexidades apresentadas por essas instituições o que impossibilita tanto a prática gerencial como a atividade organizacional.

Mintzberg (2009) trata estas singularidades e particularidades como burocracias profissionais. Essas organizações denominadas de burocracias profissionais são dotadas de profissionais, com alta capacidade técnica, como é o caso dos hospitais, institutos de pesquisa, empresas de engenharia avançada e com certeza das Universidades. Em relação a isso, "não apenas os profissionais controlam o seu próprio trabalho, mas também procuram o controle coletivo das decisões administrativas que os afetam” (MINTZBERG, 2009, p.220).

As organizações públicas, por sua vez, apresentam alto grau de complexidade, e as universidades estão inseridas nesse sistema. Guerreiro (2010) enfatiza que o papel do Administrador como gestor de organizações públicas é muito importante, pois esse profissional precisa ter habilidades e conhecimentos para gerenciar equipes, traçar objetivos e definir estratégias que possibilitem um bom desempenho organizacional, proporcionando a eficácia e primando pela qualidade dos serviços prestados. Assim, desempenha tanto o papel de gestor, como o de líder, envolvendo a equipe de forma que as pessoas se sintam parte do processo e direcionando-as ao cumprimento dos objetivos traçados de forma clara e objetiva. Ainda, reforça que qualquer organização seja ela pública ou privada necessita de planejamento, método, objetivos, foco, e do profissional Administrador.

Loureiro (2015) enfatiza que devido aos recursos limitados no setor público, o papel do Administrador é tornar esse setor mais eficiente, implementando técnicas e ferramentas de gestão que potencialize esses recursos. Aumentar substancialmente a produtividade fazendo mais com menos e assim acrescentar e melhorar os serviços oferecidos aos cidadãos com uma gestão eficiente. É importante colaborar de forma sustentável, eliminar o desperdício, melhorar processos e reduzir o gasto público.

Na mesma linha de pensamento, Nardes (2015), diz ser o papel da Administração essencial para que organizações públicas e privadas se organizem de forma a atingirem seus objetivos e metas primordiais. Qualquer organização necessita de planejamento, organização, direção e controle, ferramentas estas inerentes à Administração e que, possibilitam uma forma mais eficiente de utilização dos recursos disponíveis, buscando assim a eficácia. Nesse 
sentido, ressalta a importância do Administrador que ao desempenhar sua profissão, tem muito a contribuir não só com o progresso da instituição em que atua, mas com uma nação melhor desenvolvida e com uma sociedade mais justa. Desse profissional é requerida uma formação eclética, com conhecimentos e habilidades em diversas áreas e principalmente em aspectos sociais. É ele que possui as condições adequadas para alavancar o crescimento do país e contribuir para a igualdade e justiça social.

É importante ressaltar que o CFA (Conselho Federal de Administração) vem fazendo um trabalho contínuo a respeito da valorização do papel do Administrador em instituições públicas, buscando assim uma atuação mais efetiva no setor. Para Lemos (2015), os Administradores têm competência para mudar o cenário atual que se encontra a Administração Pública, para isso precisam se colocar em posição estratégica dentro das organizações governamentais e utilizarem a ciência da administração como ferramenta de mudança.

\section{RECURSOS METODOLÓGICOS}

\subsection{DELINEAMENTO DA PESQUISA}

O presente estudo constitui-se de uma pesquisa qualitativa, a qual segundo Gil (2007) se detém na busca aprofundada na tentativa de compreender um grupo social uma organização. Complementando, Godoy $(1995$, p.58) diz que a pesquisa qualitativa [...]

[...] parte de questões ou focos de interesses amplos, que vão se definindo à medida que o estudo se desenvolve. Envolve a obtenção de dados descritivos sobre pessoas, lugares e processos interativos pelo contato direto do pesquisador com a situação estudada, procurando compreender os fenômenos segundo a perspectiva dos sujeitos, ou seja, dos participantes da situação em estudo.

Quanto ao seu conteúdo, trata-se de uma pesquisa de caráter exploratório-descritivo, a qual tem como objetivo uma maior aproximação com o problema a fim de torná-lo mais familiar, mais explícito ou a construir hipóteses (GIL, 2007). Ainda, a pesquisa descritiva requer que o pesquisador possua diversas informações sobre o que necessita pesquisar. Dessa forma, esse tipo de estudo visa descrever os fatos e fenômenos de determinada realidade (TRIVIÑOS, 1987). Corroborando, Prodanov e Freitas (2013, p.52), acrescentam

Tal pesquisa observa, registra, analisa e ordena dados, sem manipulá-los, isto é, sem interferência do pesquisador. Procura descobrir a frequência com que um fato ocorre, sua natureza, suas características, causas, relações com outros fatos. 


\subsection{OPERACIONALIZAÇÃO DA PESQUISA}

Após definir o local em que a pesquisa seria realizada - FURG -, passou-se então à escolha dos integrantes da universidade que participariam das entrevistas. Sendo assim, foram selecionados 15 (quinze) profissionais Administradores que atuam ou atuaram nas Unidades Acadêmicas da Universidade pesquisada, categorizados como Servidores Técnicos Administrativos em Educação, classe E. No entanto, cabe ressaltar, que dos 15 (quinze) selecionados, apenas 9 (nove) responderam à pesquisa.

É importante comentar que desses 9 (nove) que responderam, 3 (três), a pedido ou a convite, já não se encontram mais trabalhando em Unidades Acadêmicas e sim nas Unidades Administrativas da Universidade. Primeiramente, realizou-se contato com os possíveis sujeitos, por meio de endereço eletrônico e telefone, explicando o objetivo do estudo e solicitando a participação dos mesmos. Posteriormente foram enviados os questionários por email para que assim pudesse ocorrer a coleta dos dados.

\subsection{O DISCURSO DO SUJEITO COLETIVO (DSC)}

A análise dos dados foi realizada por meio do Discurso do Sujeito Coletivo (DSC). Essa técnica assemelha-se a um quebra-cabeça, busca reconstruir, com pedaços de discursos individuais, os discursos-síntese necessários para expressar um determinado modo de pensar ou um imaginário específico acerca de um fenômeno (LEFÉVRE; LEFÉVRE, 2005). Trata-se de uma técnica de tabulação e organização de dados qualitativos, desenvolvido por (LEFÉVRE; LEFÉVRE, 2005). no fím da década de 90, e tem como fundamento a teoria da Representação Social. Essa técnica consiste em um discurso-síntese elaborado com partes de discursos de sentido semelhantes, por meio de procedimentos sistemáticos e padronizados.

A técnica do DSC consiste ainda em analisar o material escrito coletado, extraindo-se de cada um dos questionários as ideias centrais e ancoragens, assim como suas correspondentes expressões-chave, que compõem um ou vários discursos-síntese, na primeira pessoa do singular. Dessa forma, o sujeito coletivo expressa-se por meio de um discurso emitido no que se poderia chamar de primeira pessoa coletiva do singular, pois, várias pessoas discursaram sobre determinado tema, mas não formam um "nós", e sim um "eu coletivizado" (LEFÉVRE; LEFÉVRE, 2005). Assim, representa uma mudança nas pesquisas qualitativas porque permite que se conheça os pensamentos, representações, crenças e valores de uma coletividade sobre um determinado tema, utilizando-se de métodos científicos. 


\section{O PAPEL DO ADMINISTRADOR NA ESTRUTURA ACADÊMICA DA UNIVERSIDADE FEDERAL DO RIO GRANDE: UMA ANALISE COM BASE NO DISCURSO DO SUJEITO COLETIVO DOI: http://dx.doi.org/10.5007/1983-4535.2018v11n2p1}

Nesse sentido, o Discurso do Sujeito Coletivo (DSC) é um discurso-síntese redigido na primeira pessoa do singular, a partir de trechos de discursos individuais. Devem aparecer em itálico para indicar que se trata de uma fala ou de um depoimento coletivo. Ainda, como técnica de processamento de dados com vistas à obtenção do pensamento coletivo, o DSC dá como resultado um painel de discursos de sujeitos coletivos, justamente para sugerir uma pessoa coletiva falando como se fosse um sujeito individual de discurso (LEFÈVRE; LEFÈVRE, 2005). De acordo com os autores em questão, essa forma de apresentação de resultados de pesquisa confere muita naturalidade, espontaneidade, vivacidade ao pensamento coletivo.

Para elaborar o DSC parte-se dos discursos em estado bruto, que são submetidos a uma análise inicial que os decompõe, assinalando as expressões-chave, extraindo as principais ancoragens e/ou ideias centrais, culminando numa síntese que reconstitui discursivamente a representação social (LEFÉVRE; LEFÈVRE, 2005), conforme as definições a seguir:

Expressões-Chave (ECH), são pedaços, trechos ou transcrições literais do discurso, que devem ser sublinhadas ou coloridas pelo/a pesquisador/a, e que revelam a essência do depoimento ou, mais precisamente, do conteúdo discursivo dos segmentos em que se divide o depoimento, geralmente correspondem às questões de pesquisa. "As expressões-chave são uma espécie de prova discursiva-empírica da verdade das ideias centrais e das ancoragens e vice-versa" (LEFÉVRE; LEFÈVRE, 2005, p. 17).

Ideias centrais (IC), é um nome ou expressão linguística que revela e descreve, de maneira mais sintética, precisa e fidedigna possível, o sentido de cada um dos discursos analisados e de cada conjunto homogêneo de $\mathrm{ECH}$, que vai dar nascimento, posteriormente, ao DSC. É importante assinalar que a IC não é uma interpretação, mas uma descrição do sentido ou de um conjunto de depoimentos.

Ancoragem, é a manifestação linguística explícita de uma dada teoria, ou ideologia, ou crença que o/a autor/a do discurso professa e que, na qualidade de afirmação genérica, está sendo usada pelo/a enunciador/a para enquadrar uma situação específica. (LEFÉVRE; LEFÈVRE, 2005), expressam que quase todo discurso tem uma ancoragem na medida em que está quase sempre alicerçado em pressupostos, teorias, conceitos e hipóteses. Além das figuras metodológicas descritas acima, na construção do DSC devem-se considerar os seguintes princípios:

Coerência, significa a agregação de pedaços isolados de depoimentos para formar um todo discursivo coerente, em que cada uma das partes se reconheça enquanto constituinte desse todo, e o todo constituído por essas partes.

Posicionamento próprio, cada discurso deve sempre expressar um posicionamento próprio, distinto, original, específico sobre o tema que está sendo pesquisado. 
Tipos de distinção entre os DSCs, quando uma resposta apresenta mais de um DSC, os mesmos podem ser distinguidos por critérios de diferença/antagonismo ou pelo de complementaridade. Quando se trata de discursos diferentes, a apresentação deles, em separado, é obrigatória; quando se trata de discursos complementares, a apresentação dos discursos depende do/a pesquisador/a querer resultados mais detalhados ou mais genéricos. Há discursos que não são iguais, mas que não constituem cadeias argumentativas inconciliáveis; então, podem ser reunidos sem provocar contradição ou incoerência. Pode-se, também, separá-los quando se quer realçar matrizes de posicionamento.

Produzindo uma "artificialidade natural", é como se uma só pessoa falasse por um conjunto de pessoas, traduzindo uma construção artificial. Para fazer com que o discurso coletivo pareça individual, devem-se „limpar ${ }^{\text {ee }}$ as particularidades dos pedaços selecionados de um relato, encadeando narrativamente os discursos de modo que apresentem uma estrutura sequencial clara e coerente. "Para a construção do DSC, é preciso aproveitar todas as „peças ${ }^{e e}$, isto é, todas as ideias presentes nos depoimentos para que a figura não fique incompleta; entre as ,peças ${ }^{\text {ee }}$ repetidas ou muito semelhantes, escolhe-se apenas um exemplar" (LEFÉVRE; LEFÈVRE, 2005, p.21).

Diante do exposto, para elaborar os Discursos do Sujeito Coletivo presentes nessa pesquisa, em um primeiro momento foi realizada a leitura dos questionários respondidos por cada Administrador. Após, uma segunda leitura foi realizada, com o intuito de identificar as expressões-chave. Dessa maneira, tais expressões foram sendo destacadas e retiradas dessas as ideias centrais, passando posteriormente para a elaboração do DSC correspondente. Em uma segunda etapa foi estabelecido um diálogo com os DSCs, articulando-os com as reflexões e considerações dos autores deste estudo, utilizando como embasamento a revisão de literatura efetuada anteriormente.

Com esse intuito, buscou-se estruturar as informações obtidas de acordo com critérios pré-estabelecidos, com o intuito de filtrar os dados obtidos, seguindo então determinados critérios. Dessa forma, os resultados serão estruturados da forma como estão apresentados no Quadro 1: 
Quadro 1 Quadro-síntese das Categorias de Análise

\begin{tabular}{|c|c|}
\hline Indicador & Ideias Centrais \\
\hline $\begin{array}{l}\text { Percepção do Administrador acerca do } \\
\text { entendimento do superior imediato em relação ao } \\
\text { papel a ser desempenhado pelos mesmos. }\end{array}$ & $\begin{array}{l}\text { Desconhecimento ou conhecimento equivocado; } \\
\text { Conhecimento mais aproximado; }\end{array}$ \\
\hline $\begin{array}{l}\text { Relação entre as funções desempenhadas e a } \\
\text { análise e descrição do cargo de Administrador. }\end{array}$ & $\begin{array}{l}\text { A descrição do cargo é ampla, mas na maioria } \\
\text { das vezes as funções não estão de acordo; } \\
\text { Não em sua totalidade, mas na maioria das vezes } \\
\text { estão de acordo com o cargo; }\end{array}$ \\
\hline $\begin{array}{l}\text { Realização profissional do Administrador em } \\
\text { relação ao papel desempenhado nas Unidades } \\
\text { Acadêmicas. }\end{array}$ & $\begin{array}{l}\text { Diante de algumas possibilidades, o } \\
\text { administrador tem tido satisfação profissional; }\end{array}$ \\
\hline $\begin{array}{l}\text { Expectativa para o futuro em relação ao } \\
\text { profissional Administrador nas Unidades } \\
\text { Acadêmicas. }\end{array}$ & $\begin{array}{l}\text { Existe uma expectativa positiva para o futuro do } \\
\text { profissional; } \\
\text { Não existe uma expectativa positiva para o futuro } \\
\text { do profissional; }\end{array}$ \\
\hline
\end{tabular}

Fonte: Elaborado pelos autores (2016)

\section{RESULTADOS E DISCUSSÕES}

Nesta seção buscou-se descrever, interpretar e analisar os dados obtidos referentes à percepção dos Administradores acerca do papel que desempenham nas Unidades Acadêmicas (UA's) da Universidade Federal de Rio Grande (FURG). Apresenta-se os indicadores que foram propostos aos entrevistados, a formação dos respectivos discursos dos Administradores participantes e as devidas discussões, com base no Discurso do Sujeito Coletivo (DSC).

\subsection{PERCEPÇÃO DO ADMINISTRADOR ACERCA DO ENTENDIMENTO DO SUPERIOR IMEDIATO EM RELAÇÃO AO PAPEL A SER DESEMPENHADO PELOS MESMOS}

Ideia central: Tinha desconhecimento ou conhecimento equivocado do papel a ser desempenhado pelo Administrador.

DSC: Eu acredito que ele não tinha muita clareza do papel do administrador
na UA, nem do fazer de um Administrador. Tinha a noção de que era um
cargo de assessoria à direção, que tinha uma importância, mas ele não tinha
clara a definição do que este profissional deveria fazer. Esperava que este
fosse um resolvedor de problemas, que fizesse o que os outros servidores
não queriam fazer. Não sabia certo qual seria o papel, se era de secretário
executivo, de secretário da direção, um secretário mais qualificado e 
deixando às vezes, a cargo do secretário geral a definição deste papel, o que não fazia parte de suas atribuições. Entendo que esta situação se apresentou devido não haver por parte da Universidade um aporte para definição desse papel.

O discurso acima apresenta falas que remetem ao desconhecimento do papel do Administrador por parte da chefia que relata falta de aporte da Universidade, o que causa estranheza devido ao fato de existir um Memorando Circular com data de 14 de janeiro de 2010, onde consta que no dia 13 de janeiro do referido ano o atual Reitor da Universidade, reuniu-se com os Diretores das Unidades Acadêmicas para comunicar que os Administradores estavam sendo nomeados pela Universidade. Consta também que é imprescindível que desde a entrada dos Administradores nas Unidades Acadêmicas, se tenha clareza sobre as funções que os mesmos deverão desempenhar, dentro de suas atribuições profissionais, cuja descrição de atividades típicas do cargo foi passada a cada um dos Diretores.

Sendo assim, pode-se pensar que além da suposta falta de clareza deste papel, existisse talvez um receio de perda de poder e também possível falta de habilidade técnica gerencial. Bergue (2010) tem a visão de que as organizações públicas se definem por ser um espaço complicado, onde grupos e pessoas estão em constantes disputas por espaços. Os interesses são bastante diferenciados e a natureza das relações de poder conflituosas.

Do mesmo modo, Vieira e Vieira (2004), corroboram enfatizando que essas duas estruturas colaterais (acadêmica e administrativa), que deveriam ter coesão em sua forma de trabalho, buscando sempre o melhor para a instituição em termos de alcance de objetivos, acabam se envolvendo em disputa de interesses. Esta disputa parece acontecer muito claramente nas IES e consequentemente poderá causar influencia na ação do Administrador.

Ideia central: Tinha um conhecimento mais aproximado do papel a ser desempenhado pelo Administrador.

DSC: Acredito que tinha noção de que o papel do administrador era de assessor, supervisor, planejador, organizador e controlador. Ele resolveria as questões de compras, de infraestrutura da unidade executando e controlando o processo. Por outro lado, percebe-se que algumas chefias tinham uma noção mais aproximada do papel desses profissionais, noção esta que vem mais ao encontro da descrição sumária do cargo de Administrador prevista no Edital $n^{\circ} 01$ publicado no diário Oficial da União em 2009, em virtude do concurso conforme descrição abaixo:

Administrador: planejar, organizar, controlar e assessorar as organizações nas áreas de recursos humanos, patrimônio, materiais, informações, financeira, tecnológica, entre outras; implementar programas e projetos; elaborar planejamento organizacional; promover estudos de racionalização e controlar 
o desempenho organizacional; prestar consultoria administrativa. Assessorar nas atividades de ensino, pesquisa e extensão (FURG, 2009 p. 2).

Em vista do citado acima, considera-se que o profissional administrador tem como foco o planejamento, a execução e o controle de estratégias. Mas parece-nos que as funções a eles designadas nas UA's estão mais voltadas à execução de tarefas, as quais poderiam ser realizadas por qualquer outro técnico administrativo. Pode-se dizer que se distanciam muito das elencadas na descrição do cargo publicada no DOU em 2009 e nem perto estão, das atribuições elencadas na Lei no 4769/65.

\subsection{RELAÇÃO ENTRE AS FUNÇÕES DESEMPENHADAS E A ANÁLISE E DESCRIÇÃO DO CARGO DE ADMINISTRADOR}

Ideia central: A descrição do cargo é ampla, mas na maioria das vezes as funções desempenhadas não estão de acordo.

DSC: Eu entendo que na sua maioria não estavam de acordo com o cargo, pois a chefia queria que o administrador executasse uma série de tarefas operacionais e na realidade eu deveria me dedicar apenas ao planejamento e organização, bem como assessorar tomadas de decisão de forma estratégica dentro da unidade. A descrição do cargo é bem ampla e menciona atividades de gestão e pensamento estratégico, mas, por mais que eu tentasse pensar estrategicamente, acabava me envolvendo em questões operacionais. As poucas funções que pude desempenhar no meu cargo até hoje foram atividades de organização e controle, quase nada de planejamento. O único papel mais próximo de um gestor era quando me solicitavam relatórios sobre as cargas horárias para uma análise de como estava à situação no Instituto, mas era um trabalho sempre "engavetado". Na realidade, não considero que as unidades acadêmicas façam gestão.

Mais uma vez pode-se perceber que as funções desempenhadas pelos Administradores estão longe das descritas no cargo e que em sua maioria executam tarefas que não necessariamente precisariam de conhecimento técnico para tal. No entendimento de Corrêa (2013), o papel do Administrador vai muito além, ou seja, ele necessita cuidar e desenvolver pessoas, buscando um maior comprometimento com os objetivos não só econômicos, mas políticos, sociais, culturais e principalmente, envolver-se com questões de cunho ambiental, procurando atender as normas de sustentabilidade e por fim satisfazer as necessidades de uma sociedade. Desse profissional é requerida uma formação eclética, com conhecimentos e habilidades em diversas áreas. É ele que possui as condições adequadas para 
alavancar o crescimento do país e contribuir para a igualdade e justiça social (NARDES, 2015).

Ideia central: Na maioria das vezes as funções desempenhadas estão de acordo com o cargo.

DSC: Creio que sim, pois tenho trabalhado com controles de orçamentos, compras de bens e diárias e passagens, controle patrimonial, distribuição de bens, questões táticas vinculadas à infraestrutura, e muito ativamente no planejamento da unidade, o qual é desmembrado em subprojetos, dos quais participo de todos e tenho coordenação nos trabalhos de alguns. As funções que desempenho estão elencadas na análise e descrição do cargo do administrador, embora contemple uma parcela pequena do que nela consta. Mas cabe ressaltar que estou conseguindo desenvolver minhas atividades profissionais dentro da descrição do cargo por que diariamente reafirmo para a equipe de professores e técnicos, bem como minha chefia imediata, minha função de técnico de nível superior. Sendo assim, mesmo que não as execute na sua totalidade, uns $90 \%$ é possível.

No discurso acima, identifica-se que alguns Administradores acreditam que as atividades por eles desenvolvidas nas Unidades Acadêmicas estão de acordo com as descritas no cargo, e que conseguem executá-las não em sua totalidade, mas em um percentual bem elevado. Nota-se também, que o Administrador precisa fazer um trabalho diário de valorização do seu papel, enquanto técnico de nível superior, o que se tivesse ficado bem claro às chefias, talvez não fosse necessário. Mas, percebe-se que as atividades em sua maioria são de execução e que estão aquém de suas capacidades. Para confirmar a ideia do parágrafo anterior, Soares e Rosenberg (2009) reforçam que o Administrador possui diversas habilidades e capacidades como atitude, imaginação, responsabilidade, capacidade de ação diante de situações diversas, praticidade e também é um profissional generalista que está em formação constante. Além disso, trata-se também de um profissional com capacidade empreendedora, habilidades interpessoais e gerenciais. Sendo assim, percebe-se certa limitação referente à aplicação dessas habilidades em relação as atividades por eles desenvolvidas nas UA's. Ainda, acentuam ser muito importante o Administrador ter conhecimento político além de suas atribuições legais. O Administrador não deve incorporar somente o papel de ser o executor, mas também o construtor de políticas públicas e trabalhar com ética e seriedade nessa construção.

Nesse caso, percebe-se que a Administração Superior da Universidade em estudo, necessita ser mais efetiva no reconhecimento da figura do Administrador como agente 
político, capaz de efetivar mudanças por meio das pessoas, pois cabe a ela solicitar a presença do profissional em atividades que condizem com sua função, não como executor, mas como propositor e construtor de políticas adequadas ao desenvolvimento e crescimento da Universidade, em prol do bem comum.

\title{
4.3 REALIZAÇÃO PROFISSIONAL DO ADMINISTRADOR EM RELAÇÃO AO PAPEL DESEMPENHADO NAS UNIDADES ACADÊMICAS
}

Ideia Central: Diante de algumas possibilidades, o Administrador tem realização profissional.

\begin{abstract}
DSC: Existe realização diante da possibilidade de trabalhar mais na minha área. O papel desempenhado me trouxe possibilidade de conhecer melhor a Universidade, de legitimar minha função como administradora, de envolverme em assuntos variados. Hoje, me realiza muito profissionalmente, isto também se dá pelo fato que percebo a aceitação de toda proposição que faço quanto ao funcionamento dos processos de trabalho. Tenho total apoio da chefia imediata, esta entende que, o conhecimento adquirido na graduação bem como o adquirido pela experiência profissional anterior ao atual cargo traz uma grande qualidade na resolução das demandas solicitadas.
\end{abstract}

No discurso acima, os Administradores asseguram essa realização relacionando-a ao momento que trabalham mais nas suas funções, ou seja, nas que foram elencadas através da descrição do cargo. Também se sentem satisfeitos com as possibilidades que lhes foram dadas em circular nos diversos ambientes da Universidade, e assim possuírem a possibilidade de um conhecimento mais geral do funcionamento da mesma. Fica evidente também, a satisfação relacionada ao apoio total da chefia e a valorização das experiências de trabalhos anteriores na melhoria da qualidade das atividades atuais.

Nesse âmbito, Santos (2015), entende que realização no trabalho é relativa, o que é bom para alguns poderá não ser para outros. Um dos principais problemas encontrados nas instituições está conexo a relações humanas. O Administrador pode desempenhar o papel de mediador de conflitos, pois tem habilidades para tal e assim construir um clima propício à realização no trabalho. No entanto, o apoio da chefia para a construção desse clima positivo tende a ser indispensável.

Ideia Central: Motivada por diversos fatores, não tem havido realização profissional do Administrador.

DSC: Não há satisfação profissional, sinto que há um subaproveitamento da capacidade e da competência técnica. Apesar de buscar sempre pensar estrategicamente nunca consigo efetivamente apresentar as ideias, pois antes já me 
interrompem com a alegação de que minha função é nova e não sei como as coisas funcionam e como são as pessoas dentro da unidade. Solicitam-me a resolver problemas que estão além da minha capacidade técnica o que me traz insegurança e frustração. Na medida do possível tento implementar novas ideias, como forma de buscar alguma satisfação. Sinto uma estagnação profissional, não tenho nenhuma liberdade de atuação. Foram 6 meses em que tentei atuar o mais próximo possível de minhas reais atribuições, mas sempre sem sucesso, criando apenas mais desmotivação. Então pedi troca de lotação da Unidade Acadêmica.

As falas do discurso acima são preocupantes, visto que alguns dos Administradores se dizem insatisfeitos. Estes estão tentando pensar e agir estrategicamente, mas, sem sucesso. Parece que as pessoas não estão querendo ouvir ideias novas, mesmo vindas de um profissional preparado para a gestão, que estão com o sentimento de que sempre foi feito assim, e não entendem o porquê de um novato querer mudar. Essa tendência é bem característica no serviço público. Com isso o Administrador tem se sentido estagnado, amarrado e sem perspectivas de liberdade de atuação, buscando assim a troca de lotação da Unidade Acadêmica.

Refletindo sobre o discurso acima e sobre a satisfação que o trabalho traz para o indivíduo, pode-se dizer que, de acordo com o conjunto de sentimentos benéficos que estes apresentam em relação ao mesmo, e quanto maiores forem os fatores de satisfação, maior poderá ser o empenho do profissional em prestar um trabalho de qualidade. Outros fatores devem ser levados em consideração como a autonomia para tomar decisões, o reconhecimento e o próprio sentimento de orgulho do profissional em trabalhar em determinada instituição, aproveitando o que de bom ela pode oferecer para seu crescimento pessoal e profissional (NUNES et al, 2010). Na Universidade em estudo, percebe-se que essa qualidade de serviço pode vir a cair, devido à frustração que alguns profissionais dizem estar sentindo. É bem provável que estes comecem a colocar os seus interesses particulares em primeiro plano, vindo à função de servidor público a ser prejudicada e assim o objetivo inicial de se ter um Administrador em cada Unidade Acadêmica para melhoria da gestão, correr o risco de se perder totalmente.

\subsection{EXPECTATIVA PARA O FUTURO EM RELAÇÃO AO PROFISSIONAL ADMINISTRADOR NAS UA'S}

Ideia Central: Existe uma expectativa positiva para o futuro do profissional.

DSC: Penso primeiramente que esta figura seja reconhecida institucionalmente como o profissional que tem na sua formação inicial as competências necessárias para trazer melhoria nos processos. A partir daí, acredito que os administradores 
terão sua competência profissional melhor aproveitada na gestão da universidade como um todo, lotados nas pró-reitorias e assessorando as UAs em assuntos específicos. Sonho que o administrador de unidade acadêmica possa ser um propositor das políticas institucionais e que auxiliando nessa construção junto a administração superior, possa desenvolver um ambiente organizacional muito mais comprometido, eficiente e feliz. Acredito que aos poucos, todos os administradores estarão conseguindo exercer o seu papel de acordo com as funções que realmente tem formação.

A ideia que se tem a partir das falas no discurso acima é de que há a esperança de reconhecimento da figura do Administrador institucionalmente, de que os gestores da Universidade e das UA's entendam que o Administrador tem as competências e formação necessárias para a melhoria da gestão dessas. Existe o sonho de que o profissional seja um propositor de políticas institucionais e assim venha contribuir de forma mais eficiente com a organização em geral. Fica evidente também, o anseio de que o Administrador venha a exercer o seu papel de forma clara, estruturado e voltado às funções determinadas na análise e descrição do cargo bem como na legislação.

Nesse sentido, Soares e Rosenberg (2009) corroboram dizendo que se tem agregada a profissão do Administrador, habilidades bem diversificadas que são consideradas fundamentais para o bom desenvolvimento do exercício da profissão. A diversidade de fazeres atribuídos ao dia a dia do Administrador, bem como a amplitude do seu campo de atuação e formação, podem ter causado certa dificuldade de entendimento do real papel desse profissional dentro das UAs, mas a expectativa é positiva.

Ideia Central: Não existe uma expectativa positiva para o futuro do profissional.

DSC: Não tenho expectativas de que ocorram alterações significativas no papel do Administrador, pois já se passaram 5 anos. Acredito que se não houver uma legitimação do cargo nas unidades acadêmicas, com uma definição clara de papéis e linhas de comando, além de uma motivação financeira, haverá um esvaziamento desses profissionais nessas unidades, pois não havendo um fortalecimento de seu trabalho, eles tendem a buscar áreas onde serão mais bem quistos e aproveitados. Verifico que a situação de muitos melhorou em função de trocas de gestão. Ao mesmo tempo que tenho esperanças que ocorra o mesmo com a unidade na qual trabalho, vejo o futuro sempre como muito complicado pois estamos à mercê da troca de gestão. Cada um dos 13 administradores enfrenta realidades diferentes, ficando sempre à mercê das decisões dos diretores eleitos. Acho que se a Universidade não dedicar atenção aos administradores aos poucos todos vão pedir para sair das unidades, por serem subutilizados. Enquanto não houver uma ação por parte da gestão superior no sentido de regulamentar as atividades dos administradores de unidades acadêmicas, nada mudará. Infelizmente não enxergo muitas expectativas de mudança no papel do administrador na unidade acadêmica. Temo que as atitudes e as próprias limitações de colegas desta função, bem como a desmobilização do grupo de Administradores tenham desqualificado o papel do Administrador de Unidade Acadêmica em relação ao objetivo inicial. Penso que a dificuldade que tiveram em adaptar-se aos diferentes perfis de gestor; de entender que o Administrador é um assessor do gestor e um executor e, não o gestor, somado 
a falta de padronização dos papéis nas diferentes Unidades Acadêmicas enfraqueceu o resultado esperado na atuação desse Administrador. Os destaques são individuais, sendo influenciado mais pelo perfil, experiência profissional e identificação com a profissão e o serviço público.

De acordo com o discurso acima, evidencia-se uma perspectiva muito negativa em relação ao futuro desses profissionais nas UA's, percebe-se que já se passou algum tempo e que não houve mudanças significativas em relação à legitimação desse cargo, clareza das funções, incentivo financeiro e que tudo isso poderá levar a um esvaziamento desses 13 profissionais das UA's da Instituição. É notório o sentimento de que, com a troca de Diretores nas UA's a situação tende a piorar ou melhorar, que o Administrador está sempre à mercê dos Diretores. Também é citada uma fala em relação a atitudes e limitação dos profissionais, o que vem a prejudicar o desenvolvimento das atividades, bem como, a não adaptação do profissional a diferentes chefias e o não entendimento de que o profissional é um simples assessor e não o gestor. Um ponto importante que se verificou foi à desmobilização do grupo de administradores que se constituiu informalmente para apoio mútuo, para melhor padronização das atividades exercidas nas UA's e principalmente para lutar pelo reconhecimento da profissão na Universidade.

É importante comentar, que nos arquivos do grupo de Administradores que se reuniam informalmente, existe uma minuta de documento construída pelos profissionais, com o intuito de apresentarem à Reitoria da época, uma proposta de Coordenação Administrativa. Esse documento buscava construir um papel mais aproximado, uma maior autonomia e uma padronização dos fazeres dos profissionais Administradores dentre todas as Unidades Acadêmicas. Em 31 de agosto de 2012, foi marcada uma reunião no Gabinete do Reitor e a proposta foi apresentada e entregue em mãos. A proposta foi bem aceita, mas devido à eleição para troca de Reitoria que se aproximava, foi prometido pelos gestores da época que a pauta estaria nas discussões de transição. A mesma proposta também foi levada aos futuros candidatos à Reitoria. Mas, passados mais de três anos desde a entrega do documento, além das promessas, nada de efetivo foi feito.

\section{CONSIDERAÇÕES FINAIS}

Primeiramente destaca-se que o objetivo do estudo foi atingido, uma vez que foi possível identificar a percepção dos Administradores acerca do seu papel nas Unidades Acadêmicas da Universidade Federal do Rio Grande. 
Constatou-se a falta de clareza e até desconhecimento acerca do papel desempenhado pelos mesmos por parte da Direção das Unidades, bem como a falta de suporte por parte da Administração Central da Instituição para o desenvolvimento de um trabalho mais voltado àquilo que está descrito no cargo de Administrador e que foi elencado no Edital do concurso.

A análise dos dados, por meio do Discurso do Sujeito Coletivo, forneceu condições para perceber os diferentes entendimentos sobre o fazer do Administrador nas Unidades Acadêmicas e a dificuldade de padronização das atividades desse profissional, bem como a necessidade de apoio da Instituição na construção de uma proposta sólida para aproximar esses papeis dentro das Unidades.

O fazer de cada Administrador dependeu muito do entendimento de cada Diretor, ficando a critério desse as suas atribuições, dificultando assim a consolidação das atividades e acarretando um possível prejuízo na melhoria contínua do processo de gestão das Unidades Acadêmicas.

Percebeu-se, ainda, que alguns Administradores conseguiram fazer com que a proposta de melhoria na gestão das Unidades Acadêmicas acontecesse, embora de uma forma muito lenta e superficial, e que outros desanimaram diante das dificuldades e acabaram pedindo troca de lotação para Unidades Administrativas. Uns disseram estar satisfeitos, mas sonham com a valorização do profissional e com o melhor aproveitamento de suas competências, enquanto outros, após passar 5 anos, já perderam as esperanças de que algo possa vir a mudar.

Diante do mencionado, é importante destacar que a profissão de Administrador se consolidou dentro do contexto público; porém, paradoxalmente, temos hoje uma administração pública pouco profissional (BARATZ, 2015). Tem-se convicção de que o papel e a presença do Administrador são primordiais para o planejamento, a organização e a direção da Instituição, do controle e da otimização dos recursos existentes, e da profissionalização da gestão.

São muitos os desafios que os Administradores e a Administração Central necessitam superar para que possam influenciar, de modo positivo, a melhoria da gestão da Universidade. Mas, é importante que os obstáculos enfrentados fortaleçam esses profissionais em busca de um desafio maior, e que em nenhum momento se acomodem no desempenho de suas funções de servidores públicos, e busquem sempre a qualificação, o desenvolvimento profissional e a melhoria contínua na gestão das Unidades Acadêmicas e da Universidade como um todo. 
Acredita-se que a gestão superior deva destinar uma atenção especial a esse grupo de Administradores, fazendo-se necessário rever o papel destes, os quais foram concursados para um fim específico, mas que, em sua maioria, não está conseguindo desempenhar plenamente suas funções de acordo com as especificadas para o cargo. Trata-se de um grupo significativo de profissionais qualificados para a prática da gestão e para o trabalho em equipe, visando à melhoria da qualidade dos serviços públicos e, consequentemente, da gestão da Instituição.

\section{REFERÊNCIAS}

ANDRADE, L. M. B. de, SOUZA, I. M. de, PIRES, R. O.M. Gestão Universitária: Formação do Administrador no Brasil. XIII Coloquio de Gestión Universitária em Américas, 2013.

BARATZ, R. Uma nova revista. Master, 2015. Edição 139, março-abril-maio.

BERGUE, S. T. Gestão de Pessoas em organizações públicas. 3.ed. Caxias do Sul, RS: Educs, 2010.

BRASIL. Dispõe sobre o exercício da profissão de Técnico de Administração. Brasília, DF: Senado Federal, 1965. Disponível: $<$ http://www.planalto.gov.br/ccivil_03/leis/L4769.htm>. Acesso em: 25 de agosto de 2015.

CORRÊA, V. A. A profissão do administrador. Rio de Janeiro, 2013. Disponível em: < www.administradores.com.br>. Acesso em: 19 de janeiro de 2016.

FURG. Pró-Reitoria de Gestão de Pessoas. Edital nº 1. Rio Grande, 2009. Disponível em: www.furg.com.br. Acesso em: 09 de agosto de 2015.

GIL, A. C. Como elaborar projetos de pesquisa. 4. ed. São Paulo: Atlas, 2007.

GODOY, A. S. Introdução à Pesquisa Qualitativa e suas Possibilidades. RAE-Revista de Administração de Empresas, v. 35, n. 2, p.57-63, mar./abr. 1995.

GUERREIRO, A. C. O. A importância do papel do administrador como gestor de organizações públicas ou privadas. P@rtes. Janeiro de 2010. Disponível em:

$<$ www.partes.com.br/emrhede/papeldoadministrador.asp > Acesso em: 27 de setembro de 2015.

JUNIOR MEYER, V., LOPES, M. C. B. Administrando o imensurável: uma crítica às organizações acadêmicas. Cad. EBAPE.BR, v.13, $\mathrm{n}^{\mathrm{o}}$ 1, artigo 3, Rio de Janeiro, jan./mar. 2015.

LEFÉVRE, F; LEFÉVRE, A.M.C. O discurso do sujeito coletivo: um novo enfoque em pesquisa qualitativa (desdobramentos). 2a ed. Caxias do Sul: EDUCS; 2005.

LEMOS, V. L., Uma nova revista. Master, 2015. Edição 141, setembro-outubro. 
LOUREIRO, E. Perfil do Administrador. Master, 2015. Edição 140, junho-agosto, 2015. MINTZBERG, HENRY. Criando organizações eficazes: estruturas em cinco configurações/Henry Mintzberg; tradução Ailton Bomfim Brandão.- 2 ed.- 5 reimp.- São Paulo: Atlas, 2009.

NARDES, A. Profissionais que contribuem para o Desenvolvimento da Administração: depoimento [outubro de 2015]. Brasília: Revista Brasileira de Administração - RBA. p. 4546.

NUNES, C. M. et al. Satisfação no trabalho na percepção de enfermeiros de um hospital universitário. Rev. Eletr. Enf, v.12, n.2, p.252-257, Jun-Ago, 2010. Disponível em: https://www.fen.ufg.br/fen_revista/v12/n2/v12n2a04.htm. Acesso em: 08 fev.2016.

PRODANOV, C. C.; FREITAS, E. C. de. Metodologia do trabalho científico: Métodos e Técnicas da Pesquisa e do Trabalho Acadêmico. $2^{a}$ ed. Novo Hamburgo: Feevale, 2013.

RIZZATTI, G., JUNIOR RIZZATTI, G. Organização Universitária: mudanças na administração e nas funções administrativas. IV Colóquio Internacional sobre Gestão Universitária na América do Sul.p. 10.Florianópolis, 2004.

SANTOS, I. E. F. dos. A importância da aplicação das habilidades humanas no trabalho do administrador. In: Conselho Federal de Administração - CFA. Brasília, 2015. Disponível em: http://www.cfa.org.br/acoes-cfa/artigos/usuarios/a-administracao-como-profissao. Acesso em: 18 de janeiro de 2016.

SILVA, R. C. Gestão de Patrimônio: estudos de processos no controle de bens móveis em uma universidade federal. Rio Grande: Ed. da FURG, 2013.

SOARES, V. B.; ROSENBERG, G. O Perfil e a Formação do Administrador Público: uma Análise Curricular em Seis Instituições de Ensino Superior do Brasil. II Encontro de Ensino e Pesquisa em Administração e Contabilidade. Curitiba, PR. 15 a 17 de novembro de 2009.

TRIVIÑOS, A. N. S. Introdução à pesquisa em ciências sociais: a pesquisa qualitativa em educação. São Paulo: Atlas, 1987.

VIEIRA, E. F.; VIEIRA, M. M. F. Funcionalidade burocrática nas universidades federais: conflito em tempos de mudança. In: Revista de Administração Contemporânea. 2004. 